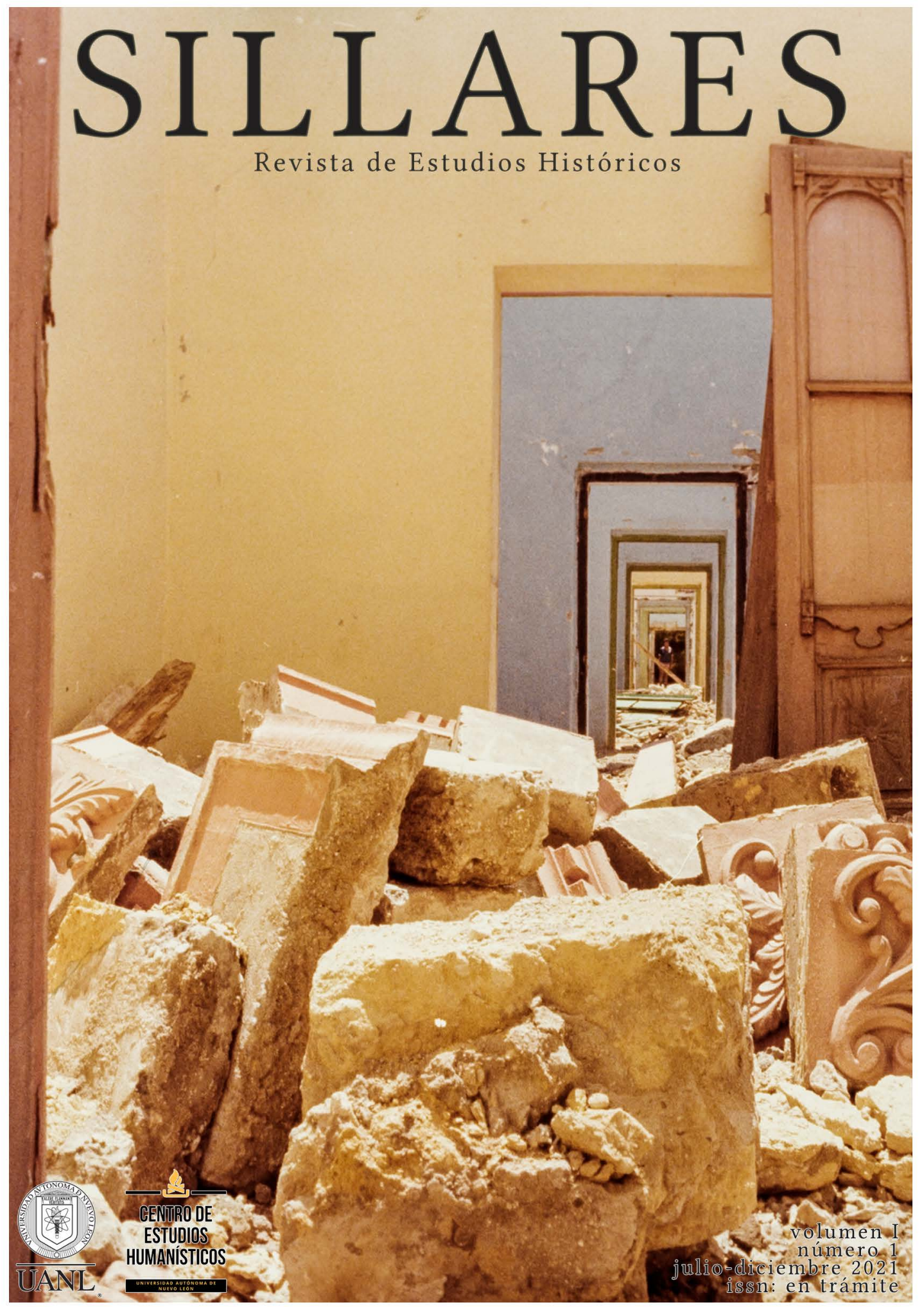




\title{
Sillares
}

Revista de Estudios Históricos

sillares.uanl.mx

\section{Los mexicotejanos frente la Comisión de Reclamaciones del estado de Texas, 1856-1858}

\section{The mexicotejanos in front of the Texas Court of Claims, 1856-1858}

\author{
Jesús F. de la Teja \\ Regents' Professor Emeritus \\ University Distinguised Professor Emeritus of Texas \\ State University \\ orcid.org//0000-0003-3744-7968
}

Recibido: 11 de diciembre de 2020

Aceptado: 8 de marzo de 2021

Publicado: 1 de julio de 2021

Copyright: (C) 2021, De la Teja Jesús F. This is an open-access article distributed under the terms of Creative Commons Attribution License [CC BY 4.0], which permits unrestricted use, distribution, and reproduction in any medium, provided the original author and source are credited.

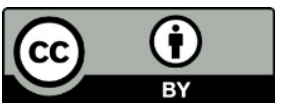

DOI: https://doi.org/10.29105/sillares1.1-5 


\section{Los mexicotejanos frente la Comisión de Reclamaciones del estado de Texas, 1856-1858}

The mexicotejanos in front of the Texas Court of Claims, 1856-1858

Jesús F. de la Teja

Regents' Professor Emeritus

University Distinguised Professor Emeritus of Texas State University orcid.org/0000-0003-3744-7968

Resumen: Después de la declaración de independencia de Texas (1836) y del tratado de Guadalupe Hidalgo (1848), los mexicanos que quedaron al norte del río Bravo tuvieron una posición ambivalente frente a la ley. En este artículo, estudio la problemática de los mexicotejanos ante la Texas Court of Claims a través de los procesos de lotificación de terrenos y analizo los rechazos de reclamaciones escritas y la desestimación de credibilidad hacia ellos. Hago tres conclusiones preliminares: primero, que estos casos reforzaron los estereotipos y el racismo; segundo, que el valor de la ciudadanía de los mexicotejanos fue puesta en duda por los comisionados anglotejanos; y tercero, que los especuladores de tierras se aprovecharon de ellos y contribuyeron al deterioro de sus derechos. En un grado considerable, los resultados de este proceso fomentaron la discriminación y segregación que continuó hasta mediados del siglo XX.

Palabras clave: Mexicotejanos; racismo; Comisión de Reclamaciones; Texas; frontera. 
Abstract: After the Texas declaration of independence (1836) and the Treaty of Guadalupe Hidalgo (1848), Mexicans who remained north of the Rio Grande had an ambivalent position before the law. In this article, I address the problem of Tejanos before the Texas Court of Claims through the land subdivision processes and analyze the rejections of written claims and the denial of credibility towards them. I made three preliminary conclusions. First, these cases reinforced stereotypes and racism; second, the Anglo-Texan commissioners questioned Tejano citizenship's value; and third, land speculators took advantage of Tejanos and contributed to the deterioration of their rights. To a considerable degree, the outcomes of this process added to the increasing discrimination and segregation that continued until the mid 20th century.

Keywords: Tejanos; racism; Court of Claims; Texas; borderlands. 


\section{Introducción}

La situación de los mexicotejanos dentro de la sociedad angloamericana tejana se deterioró progresivamente en el transcurso del siglo XIX. Las obras de Arnoldo De León, David Montejano y otros estudiosos del tema han demostrado el alto nivel de prejuicio racial confrontado por los mexicotejanos en muchas partes del estado. ${ }^{1}$ Los anglotejanos "consideraban a los mexicanos como gente de color, notaban su ascendencia indígena y los identificaban como negros dentro de la sociedad. En principio y efectivamente, a los mexicanos se le consideraba una nación relacionada a la blanca, pero una raza aparte". ${ }^{2}$ Aunque la ley les concedía igualdad con los anglotejanos, los mexicotejanos pronto se vieron, y se quedaron por más de un siglo, en condiciones de inferioridad.

\footnotetext{
${ }^{1}$ Ver, por ejemplo, William D. Carrigan y Clive Webb, Forgotten Dead: Mob Violence against Mexicans in the United States, 1848-1928 (New York: Oxford University Press, 2013); Robert J Rosenbaum, Mexicano Resistance in the Southwest: "The Sacred Right of Self-Preservation" (Austin: University of Texas Press, 1981); Jerry D Thompson, Cortina: Defending the Mexican Name in Texas (College Station: Texas A\&M University Press, 2007); Elliott Young, Catarino Garza's Revolution on the Texas-Mexico Border (Durham: Duke University Press, 2004).

2 Arnoldo De León, They Called Them Greasers: Anglo Attitudes Toward Mexicans in Texas, 1821-1900 (Austin: University of Texas Press, 1983), 104. [Nota del Autor: en este ensayo todas las traducciones son responsabilidad del autor].
}

Sillares, vol. 1, núm. 1, 2021

DOI: https://doi.org/10.29105/sillares1.1-5 
A pesar del considerable número de investigaciones sobre los mexicotejanos del siglo XIX encaminadas durante las últimas tres décadas, en particular sobre su aislamiento social, marginalización económica y privación de derechos políticos, poco se ha escrito sobre la posición de los mexicotejanos frente a la ley. Aunque por mucho tiempo se han reconocido y hasta se han aplicado ciertos aspectos del derecho español-mexicano dentro de los sistemas legales tejano y estadounidense, se han hecho pocos esfuerzos por examinar cómo la legislación tejana trataba a los mexicotejanos. ${ }^{3}$ Tanto los motivos para intentar la codificación de un tratamiento "equitativo", por un lado, como la discriminación abierta dentro del derecho tejano, por el otro, necesitan todavía ser investigados.

${ }^{3}$ Ver, por ejemplo, Mark M Carroll, Homesteads Ungovernable: Families, Sex, Race, and the Law in Frontier Texas, 1823-1860 (Austin: University of Texas Press, 2001); Jean Stuntz, Hers, His, and Theirs: Community Property Law in Spain and Early Texas (Lubbock: Texas Tech University Press, 2005); Betty Eakle Dobkins, The Spanish Element in Texas Water Law (Austin: University of Texas Press, 1959); James P Hart, "Oil, the Courts, and the Railroad Commission", Southwestern Historical Quarterly 44, núm. 3 (1941): 303-20; Walace Hawkins, El Sal del Rey: Fixing Title to. (Austin: Texas State Historical Association, 1947); Charles R Porter Jr., Spanish Water, Anglo Water: Early Development in San Antonio (College Station: Texas A\&M University Press, 2009).

DOI: https://doi.org/10.29105/sillares1.1-5 
Este ensayo presenta algunos hallazgos preliminares sobre el tratamiento legislativo en relación a los mexicotejanos. Escogí el tema de los mexicotejanos frente la Comisión de Reclamaciones $^{4}$ porque surge del trabajo que he hecho previamente sobre la especulación del suelo en la época anterior a la guerra civil norteamericana. Además, se dirige a cuestiones sobre la ambivalencia de los anglotejanos hacia el status sociolegal de los mexicotejanos durante aquella época. Mientras que el objeto y carácter de la comisión serán discutidos en torno a los reclamantes mexicotejanos, otros aspectos del funcionamiento y jurisdicción de la comisión quedan fuera del ámbito de esta obra. También me limito a los primeros dos años de la comisión, el periodo durante el cual he examinado el mayor número de fuentes. Este periodo cubre la comisión durante el tiempo en el cual la mayoría de las reclamaciones originales se presentaron y durante el cual la legislatura estatal estuvo activamente involucrada en la adjudicación de los reclamos.

\section{Los mexicotejanos y la especulación del suelo}

La forma en la que más sufrió la población mexicotejana durante el siglo XIX fue en la disminución de su acceso a la propiedad

${ }^{4}$ Court of Claims.

Sillares, vol. 1, núm. 1, 2021

DOI: https://doi.org/10.29105/sillares1.1-5 
del suelo. Como indica David Montejano en su ya clásico Anglos and Mexicans in the Making of Texas, "no solo falló el nuevo derecho americano en proteger a los mexicanos, sino que se usó como el más importante instrumento en su despojo". 5 El aspecto más estudiado de este despojo ha sido la pérdida de las mercedes de tierras en el área de la cesión tamaulipeca, esto es, la parte de Texas al sur del Río Nueces. ${ }^{6}$ Como Galen Greaser y yo señalamos en nuestro artículo sobre la comisión estatal encargada de investigar las concesiones de tierras españolas y mexicanas en esa parte del estado antes que el estado de Texas estableciera su control, el nuevo gobierno tenía un interés práctico en respetar cuantos títulos fuera posible. Abogados, ganaderos y especuladores ya habían adquirido sustanciales derechos sobre terrenos mexicanos en la región y una invalidación llana de esos títulos malograría esos nuevos intereses. El gobierno tejano enfrentaría además no solo una insurrección de los terratenientes mexicotejanos, sino también la enemistad de numerosos

\footnotetext{
${ }^{5}$ David Montejano, Anglos and Mexicans in the Making of Texas, 1836-1986 (Austin: University of Texas Press, 1987), 52.

${ }^{6}$ El primer estudioso que lidia con la cuestión del despojo de los mexicotejanos en la región del Sur de Texas fue Paul S. Taylor. Para consultar en: Paul S Taylor, An American-Mexican Frontier: Nueces County, Texas (New York: Russell \& Russell, 1971).
} 
angloamericanos influyentes que habían adquirido un interés económico en la región. Así y todo, por muchos años la legislatura se negó a aceptar la validez de aquellos títulos emitidos por las autoridades mexicanas en el periodo entre la declaración de independencia de Texas (1836) y el Tratado de Guadalupe Hidalgo (1848), señalando que la jurisdicción mexicana había vencido. ${ }^{7}$

El Sur de Texas no era el único lugar donde los mexicotejanos enfrentaban despojo y deslocalización. Menos estudiada ha sido la compraventa de derechos de suelo por reclamantes mexicotejanos y especuladores durante la época de la república. En un esfuerzo por cumplir con la promesa hecha por el gobierno rebelde de respetar los derechos a tierras de todo residente en pro de la república que había llegado a Texas antes del 2 de marzo de 1836 (fecha de la declaración de independencia), el congreso de la república organizó comisiones de tierras en todos los condados. Estas comisiones locales estaban

\footnotetext{
${ }^{7}$ Por una ley de diciembre de 1836, la República de Texas declaró el Río Bravo la frontera con México, de tal modo que el estado de Texas no reconocía el derecho de Tamaulipas o Coahuila de emitir títulos al norte del río. Galen D. Greaser y Jesús F. De La Teja, "Quieting Title to Spanish and Mexican Land Grants in the Trans-Nueces: The Bourland and Miller Commission, 18501852”, Southwestern Historical Quarterly 95, núm. 4 (1992): 464.
}

DOI: https://doi.org/10.29105/sillares1.1-5 
encargadas de repasar cada petición, tomar testimonio y emitir un certificado por la cantidad correspondiente al aprobarse la solicitud. Los especuladores se aprovecharon de los mexicotejanos necesitados, quienes habían resultado más afectados por las hostilidades entre México y Texas. Desconociendo sus prerrogativas y tentados por el dinero en efectivo que se les ofrecía, vendieron sus derechos tanto poseedores legítimos como ilegítimos. Un residente anglotejano de San Antonio, Lancelott Smithers, le reportó al comisario de la Comisión de Tierras estatal ${ }^{8}$ que:

Los ciudadanos de Laredo (como buenos tejanos) son traídos al rancho de Calvillo y otros puntos escondidos de estos contornos para jurar frente un juez su ciudadanía y otras calificaciones y para vender sus derechos, los cuales los comprantes le presentan a la comisión.

Un gran número de reclamos ya obtenidos son notoriamente fraudulentos. He visto a un mexicano recibir dinero por haber jurado ante la comisión y probar su derecho; y cualquier hombre puede ver lo mismo si abre sus ojos. Un platero de este pueblo,

\footnotetext{
8 Texas General Land Office. Este departamento del gobierno estatal se estableció durante la guerra de independencia de Texas para centralizar el proceso de distribución y documentación del territorio tejano. Sigue siendo uno de los órganos más importante del gobierno estatal e imprescindible acervo para el estudio de la época mexicana de Texas.
} 
quien actuó de jefe político bajo Santa Anna y todos lo conocen, recibió su sitio y labor. Conozco muchos mexicanos (tres dentro de una hora) quienes se fugaron como enemigos y últimamente han vuelto (dejando sus familias del otro lado del Río Grande) y han recibido sus certificados de sitio y labor. Creo que todos los soldados de Santa Anna han recibido certificados, aquellos con esposas un sitio y labor y en algunos instantes las mujeres han probado su derecho de nuevo en forma de viudas y han recibido otro sitio. ${ }^{9}$

John Pitts, en su tesis de maestría sobre el tema de la especulación en estos derechos, ha documentado la venta de millones de hectáreas por reclamantes mexicotejanos, en gran parte a especuladores angloamericanos (625,000 hectáreas sólo en 1837). ${ }^{10}$ En la conclusión de su tesis, Pitts señala que la política sobre el suelo tejano había sido un experimento en la democracia de estilo Jefferson, ${ }^{11}$ pero una política que por razones

\footnotetext{
${ }^{9}$ Citado en Jesús F. De La Teja, ed., A Revolution Remembered: The Memoirs and Selected Correspondence of Juan N. Seguín (Austin: Texas State Historical Association, 2002), 36.

${ }^{10}$ John Bost Pitts III, "Speculation in Headright Land Grants in San Antonio from 1837 to 1842" (Tesis de maestría, Trinity University, 1966), 14.

${ }^{11}$ El presidente Thomas Jefferson mantenía que la salud de la república norteamericana estaba basada en la distribución de la propiedad del suelo entre el mayor número de habitantes posible.
} 
económicas y raciales había excluido a los mexicotejanos. Ellos habían escogido "regatear su interés en la república" impulsados "por sus necesidades económicas". ${ }^{12}$ El papel voluntario (aunque inconsciente) que jugaron los mexicotejanos en estas especulaciones tuvo amplias ramificaciones. Este episodio, en el área de San Antonio, abrió las puertas a que los angloamericanos desconfiaran de los mexicotejanos como participantes en futuros esfuerzos legislativos para determinar sus Rights \& Benefits.

Sin embargo, la porción suroeste del estado no era la única zona plagada por la corrupción. Hasta en Texas oriental, donde no había mexicotejanos, el fraude y la especulación habían bajado el valor de los certificados ${ }^{13} \mathrm{y}$, en consecuencia, de los baldíos. La compraventa de certificados obtenidos fraudulentamente creció de tal modo que el congreso se vio obligado a crear en 1840 dos comisiones ambulantes para la examinación sobre la legitimidad de los certificados emitidos. El congreso autorizó a

${ }^{12}$ Pitts III, "Speculation in Headright Land Grants in San Antonio from 1837 to $1842 ", 51$.

${ }^{13}$ La distribución de tierras durante la república de Texas se basó en la emisión de certificados que no solamente se podían usar para reclamar terrenos baldíos, sino que también se podían vender, ya que el derecho existía en el instrumento y no la persona. De tal forma, se creó un gran mercado en la compraventa de todo tipo de certificados.

DOI: https://doi.org/10.29105/sillares1.1-5 
los jueces de distrito oír pleitos de aquellos a los cuales se les había rechazado su certificado por las comisiones ambulantes y la constitución estatal de 1846 denominó el primero de julio de 1847 fecha límite para emprender esa clase de demanda.

La distribución de tierras en Texas se formalizó primero bajo el régimen mexicano. Los colonos cabeza de familia que habían llegado legalmente a Coahuila y Texas tenían derecho a un sitio (aproximadamente 1,800 hectáreas). Para apaciguar a aquellos que no habían podido recibir sus terrenos antes del comienzo de la rebelión, el congreso de la república estableció que todos los que llegaron antes de la declaración de independencia tenían derecho a la cantidad de un sitio y labor (1,864 hectáreas). Al comprobar su elegibilidad, el reclamante recibiría un certificado, con el cual podía buscar y reclamar la cantidad expresada en él en cualquier parte de la república. Este programa de headrights, aunque fue disminuyendo la cantidad de tierra dotada, se mantuvo hasta los últimos días de la república. Además, este no era el único programa de repartición de tierras que se prestaba al abuso. Durante la guerra de independencia de 
Texas se había atraído a voluntarios de los Estados Unidos con promesas de tierras. El gobierno rebelde les pagó a sus militares a cosa de 130 hectáreas por cada enganche de tres meses. Después de la guerra, la abundancia de baldíos dio ocasión para premiar a los participantes en una de las importantes campañas de la guerra con una "donación" de 260 hectáreas. Sin embargo, al gobierno se le dificultó comprobar los servicios de gran número de los supuestos militantes. Muchas compañías de auxiliares habían participado en el conflicto sin plantilla, y había conflictos con la documentación que sí existía para las unidades del ejército permanente. Aparte de las reclamaciones sin mérito, también había surgido para la década de 1850 una pequeña industria de certificados falsos. En 1855, un incendio en el despacho del ayudante general de Texas, quemó casi todos los archivos militares de la época de la república. La culpa, por supuesto, recayó sobre los falsificadores, quienes nunca fueron aprehendidos. $^{14}$

14 Thomas Lloyd Miller, The Public Lands of Texas, 1519-1970 (Norman: University of Oklahoma Press, 1972), 127.

Sillares, vol. 1, núm. 1, 2021

DOI: https://doi.org/10.29105/sillares1.1-5 


\section{La Comisión de Reclamaciones}

El fraude y la especulación estaban por todos lados. Los esfuerzos por parte de la república de promover el asentamiento de sus baldíos por medio de una política del suelo generosa crearon problemas para los cuales no había remedios sencillos. Abogados y especuladores intencionalmente confundían las cosas, adquiriendo para sí mismos derechos de miles de hectáreas, al mismo tiempo disminuyendo el valor de la tierra. En un esfuerzo por acabar con los abusos, la legislatura estableció una comisión de reclamaciones en Austin, la capital del estado, la cual sería responsable de cerrar los libros de todas las reclamaciones en contra de la república.

Se estableció la Texas Court of Claims o Comisión de Reclamaciones ${ }^{15}$ de Texas, el primero de agosto de 1856 . La ley exigía el nombramiento de un comisario, que había de ser elegido por el voto de las dos cámaras de la legislatura y que debía de completar su obra el primero de enero de 1858. Él y un asistente

\footnotetext{
${ }^{15}$ Court of Claims. En inglés, la palabra "court" se puede emplear tanto en casos de instituciones de adjudicación de la ley como comisiones cuya tarea es la administración de algún proceso. En tales casos, la "corte" puede no estar bajo el cargo de un juez o magistrado, sino de un comisario o presidente. En el caso presentado aquí, la Court of Claims era una Comisión de Reclamaciones bajo el cargo de un comisario.
}

Sillares, vol. 1, núm. 1, 2021

DOI: https://doi.org/10.29105/sillares1.1-5 
debían revisar la validez de todos los certificados todavía en circulación, aceptar nuevas solicitudes para terrenos y dictaminar sobre los méritos de las solicitudes para el reemplazo de certificados perdidos y de certificados para la cantidad restante cuando un reparto no completara la cantidad original. El trabajo de la comisión fue tal que la legislatura autorizó un segundo asistente y en enero de 1858 extendió la plaza del comisario hasta el primero de septiembre de 1859. Aun con esto, la comisión no había completado su trabajo cuando llegó la segunda fecha límite y la legislatura restauró la comisión en febrero de 1860, estableciendo como nueva fecha el 31 de diciembre de $1861 .{ }^{16}$

La parte más sencilla del trabajo de la comisión era la aprobación o rechazo de los certificados en circulación. Aquellos certificados presentados para examinación eran revisados contra la documentación existente. Aquellos en posesión de certificados que fuesen rechazados por el comisionado, podían intentar validarlos emprendiendo una demanda en la corte de distrito del condado en el cual el certificado se emitió. También se limitó la capacidad de los compradores de certificados para poder

${ }^{16}$ Miller, The Public Lands of Texas, 1519-1970, 29.

Sillares, vol. 1, núm. 1, 2021

DOI: https://doi.org/10.29105/sillares1.1-5 
adquirirlos. ${ }^{17}$ Una revisión de cómo les fue a los reclamantes mexicotejanos en esta parte de las actividades de la comisión será parte de una futura investigación y queda fuera del ámbito del presente trabajo.

Un aspecto mucho más espinoso de las responsabilidades del comisario era la autoridad que tenía de aceptar solicitudes para nuevos certificados. La ley de 1856 requería que el comisario emitiera un certificado a cualquiera que presentara una prueba adecuada. La prueba consistía en una declaración jurada en la cual el reclamante demostraba que tenía residencia en Texas desde antes del 2 de marzo de 1836, que no había salido del país para evitar servicio militar, que no había ayudado al enemigo y que no había recibido anteriormente tierras bajo los términos que ahora reclamaba. También tenía que presentar dos testigos para probar su residencia. ${ }^{18}$ En aquellos casos en los cuales el comisario determinara que las pruebas no eran suficientes para emitir un certificado, éste debía mandar la solicitud, la evidencia y su dictamen a la legislatura para su resolución. La ley de enero

\footnotetext{
${ }^{17}$ John Sayles y Henry Sayles, A Treatise on the Laws of Texas Relating to Real Estate, and Actions to Try Title and for Possession of Lands and Tenements (St. Louis: The Gilbert Book Company, 1890), 243-45.

${ }^{18}$ Sayles y Sayles, 232.
}

Sillares, vol. 1, núm. 1, 2021

DOI: https://doi.org/10.29105/sillares1.1-5 
de 1858 estableció el 1 de septiembre de ese año como fecha límite para presentar reclamos originales e hizo responsable a la legislatura de evaluar las evidencias. La ley de febrero de 1860, por su parte, extendió los plazos hasta el primero de junio de 1861 para presentar una reclamación frente a una junta compuesta por la Comisión de Tierras del estado, el contralor general y el tesorero estatal. ${ }^{19}$

Las quejas de los comisarios y los debates en la legislatura evidencian la incomodidad y divisiones ocasionadas por la investigación de tales reclamaciones. Después de explicar cómo tenían evidencia de que había solicitantes y testigos que firmaban con sus nombres formularios en blanco, y que tales documentos también se vendían notariados con los nombres de solicitantes y testigos en blanco para ser llenados por el comprador, el comisario James C. Wilson escribió en su reporte del 1 de junio de 1857:

Se puede ver de lo ya dicho que en mi opinión el poder ahora en manos de este departamento para otorgar certificados originales se debe abrogar. Esa es mi cierta determinación. Tengo confianza que el número de reclamantes justos es extremadamente pequeño y mi razón no puede aceptar la propuesta que la indolencia de unas pocas personas, quienes

${ }^{19}$ Sayles y Sayles, 235-36.

Sillares, vol. 1, núm. 1, 2021

DOI: https://doi.org/10.29105/sillares1.1-5 
por muchos años no hayan solicitado un don gratuito por parte del gobierno el cual en cualquier momento podían haber realizado solo cumpliendo con la ley sobre el don, constituya razón suficiente para influir la legislación del estado, el desperdicio de su hacienda y la desmoralización de sus ciudadanos. ${ }^{20}$

Un miembro de la cámara de representantes comentó, durante la discusión sobre un proyecto de ley en pro de Lázaro Garza, que la Comisión de Reclamaciones no había hecho nada. "La ley se promulgó con tan estrictas guardas en contra del fraude que un reclamante honesto no puede recibir reparación". 21 Thomas Lloyd Miller, historiador de la política del suelo de Texas, concluye su capítulo sobre la Comisión de Reclamaciones con el siguiente comentario: "Con excesivo cuidado, pero deseando hacer justicia a todos, la Comisión de Reclamaciones de Texas averiguó los reclamos monetarios y de tierras en contra de la república y el estado de Texas". 22

\section{Los mexicotejanos y la Comisión de Reclamaciones}

Hay bastante evidencia, sin embargo, de que la Comisión de Reclamaciones no deseaba "hacer justicia a todos”. Hasta la más

${ }^{20}$ Texas General Land Office: Commissioner of Claims (GLO: CC). Report, June 1, 1857, 10.

${ }^{21}$ Austin State Gazette (ASG). "Legislative Proceedings", Nov. 30, 1857.

${ }^{22}$ Miller, The Public Lands of Texas, 1519-1970, 136.

Sillares, vol. 1, núm. 1, 2021

DOI: https://doi.org/10.29105/sillares1.1-5 
ligera revisión de los documentos de la comisión, de las actas de la legislatura y de los periódicos contemporáneos, revelan que viejas prácticas de discriminación y abuso habían surgido de nuevo. Por un lado, los mexicotejanos enfrentaban criterios más estrictos de prueba frente a la comisión, y por otro, muchos cayeron en manos de los mismos especuladores que la legislatura intentaba correr del negocio de reparto de baldíos.

El primer comisario de la Comisión de Reclamaciones, Wilson, miembro de la llamada expedición de Mier de 1842, quien se había escapado de una prisión mexicana en julio de $1843,{ }^{23}$ estableció el patrón discriminatorio en contra de los mexicotejanos. De acuerdo con la constitución del estado y el Tratado de Guadalupe Hidalgo, los tejanos de ascendencia mexicana eran ciudadanos de los Estados Unidos. En consecuencia, ni la ley de 1856 que estableció la Comisión de Reclamaciones, ni alguna otra ley previa estableció los criterios

\footnotetext{
${ }^{23}$ Inmediatamente después de la incursión del general mexicano Adrián Woll, quien ocupó a San Antonio por una semana en septiembre de 1842, una fuerza del ejército tejano y de auxiliares marcharon sobre el Bravo. Aunque el presidente Houston dio orden de que regresaran, más de 300 hombres decidieron cruzar el río y atacar las comunidades mexicanas. En un encuentro con tropas mexicanas en Mier, Tamaulipas, la expedición fue derrotada y los sobrevivientes fueron enviados a la Ciudad de México. Un fracasado intento de fuga resultó en la ejecución de uno de cada diez prisioneros.
}

Sillares, vol. 1, núm. 1, 2021

DOI: https://doi.org/10.29105/sillares1.1-5 
para probar los reclamos entre tejanos de origen angloamericano o mexicano. Pero Wilson emitió sus propias reglas para presentar y probar evidencia, incluyendo una que requería que la veracidad de cualquier testigo "mexicano" se tuviera que comprobar con testimonio de dos hombres "blancos". ${ }^{24}$

Una mayor prueba de la actitud de Wilson hacia los reclamantes mexicotejanos se encuentra en su reporte del primero de junio de 1857. Aunque los mexicotejanos formaban un pequeño porcentaje del número total de solicitantes de certificados originales, ocho de los diez ejemplos que Wilson dio de reclamaciones problemáticas eran de casos mexicotejanos. Wilson intentó usar otro ejemplo, aunque lo tachó del borrador del reporte: "De nuevo, en el caso de los herederos de Antonio Chapa, uno de los testigos le era desconocido al comisario y no se ofreció prueba de su verosimilitud". ${ }^{25}$ No es sorprendente que, de más de cien casos que Wilson le refirió a la cámara de representantes, ninguno llevaba su recomendación. En sólo dos

\footnotetext{
${ }^{24}$ ASG. "Legislative Proceedings", Nov. 30, 1857. Mucho del trabajo del comisario de reclamaciones se desconoce, pues aunque la ley requería que los papeles de la comisión fuesen depositados en la oficina de tierras del estado, ni las actas de la comisión ni las comunicaciones internas se encuentran en los archivos de la oficina.
}

${ }^{25}$ GLO: CC. Commissioner of Claims, Report, June 1, 1857.

Sillares, vol. 1, núm. 1, 2021

DOI: https://doi.org/10.29105/sillares1.1-5 
de los casos, dictaminó la comisión en favor del reclamante. Wilson no aprobó ni un solo reclamo original presentado por un mexicotejano y solo emitió un solo certificado de reemplazo por uno perdido. Cientos de casos quedaron abiertos cuando Wilson se apartó de la comisión en julio de $1857 .^{26}$

El 30 de noviembre de ese mismo año, Ángel Navarro, diputado por el condado de Béxar en la cámara de representantes del estado, hizo pública la actuación arbitraria por parte de Wilson. Lo que trajo la situación a la vista del público, fue el rechazo de Lázaro Garza en aceptar la regla del comisario de que hombres blancos debían establecer la veracidad de los testigos mexicotejanos. Según Navarro, el octogenario Garza había acertado que:

Antes de someterse a la indignidad de que su carácter o el carácter de sus testigos tuviera que ser probado por testimonio de otros hombres, de cuales él se consideraba su igual bajo las leyes, estaría dispuesto a perder hasta el último centavo y hasta la última pulgada de tierra a lo cual pudiera tener derecho. ${ }^{27}$

Garza llevó su demanda directamente a la legislatura, la cual refirió el caso a la misma comisión legislativa responsable de la

${ }^{26}$ GLO: CC. Information gathered from Old Docket, 1857-1860.

${ }^{27}$ ASG. "Legislative Proceedings", Nov. 30, 1857.

Sillares, vol. 1, núm. 1, 2021

DOI: https://doi.org/10.29105/sillares1.1-5 
Comisión de Reclamaciones. Navarro, uno de los comisionados, esclareció que sabía de la regla de Wilson por uno de los secretarios de la comisión, James O. Illingworth, quien de momento servía de comisario interino. El diputado mexicotejano, entonces, calificó la regla de arbitraria y señaló que "no [era] requerida por la ley [y establecía] una injusta e imprudente distinción, una insidiosa discriminación donde la ley no prescribe clases". ${ }^{28}$ El 19 de diciembre de 1857, Lázaro Garza recibió su desagravio por parte de la legislatura en la forma de un sitio y labor de tierra. ${ }^{29}$

La Comisión de Reclamaciones debía concluir sus funciones para el primero de enero de 1858 y James Illingworth, el sucesor de Wilson, tenía por delante la tarea de concluir miles de casos que quedaban abiertos. De tal modo, estando la función de la comisión por vencerse, la legislatura extendió su plazo hasta el primero de enero de 1859. La extensión no vino sin un duro debate en la cámara de representantes, en el cual varios miembros argumentaron que lo único que se ganaba con la extensión era "dar unas oportunidades a aquellas personas deseando especular

\footnotetext{
${ }^{28}$ ASG. "Legislative Proceedings", Nov. 30, 1857.

${ }^{29}$ Gammel's Laws of Texas. "An Act for the Relief of Lázaro Garza”, vol. 4, pt. 3, 1189.
}

Sillares, vol. 1, núm. 1, 2021

DOI: https://doi.org/10.29105/sillares1.1-5 
en el país, lo cual nunca hubieran pensado hacer si a la comisión no se hubiera creado". ${ }^{30}$ Otro diputado fue más directo, llamando a la comisión "un chantaje sobre los derechos del pueblo". ${ }^{31}$ En un intento de satisfacer las quejas, por lo menos en parte, la nueva ley cerraba la posibilidad de hacer nuevas reclamaciones el primero de septiembre de $1858 .^{32}$

Lo claro era que la mayoría de las reclamaciones, por parte de los mexicotejanos, eran fraudulentas, y el resultado de la especulación nunca se podría probar adecuadamente. Aunque los legisladores no se dirigieron al asunto en términos raciales, durante el debate sobre la nueva ley, el comisario interino continuaba documentando las prácticas de los especuladores de esa forma. Por ejemplo, G. H. Nelson, abogado de quince reclamantes mexicotejanos, no pudo presentar ni una pieza de evidencia que el comisario considerara aceptable en ninguno de los casos. Además de la calificación inicial de "no hay prueba legal" al margen del nombre de cada solicitante, todos los casos aparecen como 'rechazados' por una de tres razones. Aparte de no

\footnotetext{
${ }^{30}$ ASG. Mr. McKinney of Travis, Legislative Proceedings, Jan. 4, 1858.

${ }^{31}$ ASG. Mr. Chilton.

${ }^{32}$ Sayles y Sayles, A Treatise on the Laws of Texas Relating to Real Estate, and Actions to Try Title and for Possession of Lands and Tenements, 236.
}

Sillares, vol. 1, núm. 1, 2021

DOI: https://doi.org/10.29105/sillares 1.1-5 
presentar prueba legal, Juana Sánchez Martínez no presentó evidencia de que era cabeza de familia. A cuatro de los reclamantes se les acusaba de haber firmado sus declaraciones juradas en blanco. El comisario encontró "la evidencia todo en blanco" en otros ocho casos. Los defectos en las reclamaciones de Enatugre Ochoa [sic] y María Victoriana Villarreal eran los más graves. En estos casos "las declaraciones juradas están en blanco en cuanto el nombre del solicitante, sin embargo, se han jurado solemnemente por dos testigos y verificado por un notario público bajo su puño y sello". ${ }^{33}$

Dos casos de especulación resaltan por su magnitud. Antony Superviele, un francés sirviendo de senador por el condado de Béxar en la sexta legislatura, también representó a más de 120 denunciantes mexicotejanos que solicitaban certificados originales. $\mathrm{Ni}$ en un solo caso el comisario o la legislatura pudo actuar en favor de sus clientes. Las anotaciones abundan acerca de que la evidencia estaba incompleta o de que ninguna prueba se había presentado. Otro francés, Xavier B. De Bray, quien se había establecido en San Antonio en 1852, tomó ventaja de su origen para hacerse abogado de 65 mexicotejanos.

${ }^{33}$ GLO: CC. Entries 336-345, Old Docket, 1857-1860.

Sillares, vol. 1, núm. 1, 2021

DOI: https://doi.org/10.29105/sillares1.1-5 
Hasta 1856 había trabajado de intérprete y traductor en San Antonio, donde había establecido el periódico El Bejareño. Para 1856 De Bray se había mudado a Austin, donde consiguió el puesto de traductor de la Comisión de Tierras antes de abrir una academia, que mantuvo hasta alistarse en el ejército de la confederación al principio de la guerra civil norteamericana. ${ }^{34} \mathrm{~A}$ pesar de todo, sus conexiones no le otorgaron un tratamiento preferente en la comisión o la legislatura. No se le aprobó ni un solo reclamo, incluyendo 22 que presentó el 30 de agosto de 1858 sin motivo aparente, dos días antes de la fecha límite. ${ }^{35} \mathrm{De}$ momento es imposible determinar cuáles casos son de especuladores que trataban de presentar reclamaciones que habían comprado y cuáles sólo buscaban estafar a inocentes, cobrando por hacer trámites que sabían que no darían resultados.

En cuanto a los mexicotejanos, los resultados de este primer periodo fueron desastrosos. De los 404 apellidos hispanos que aparecen en el registro de la comisión, aproximadamente 228 no recibieron acción alguna al no haberse recibido ninguna

${ }^{34}$ Handbook of Texas Online, Anne J. Bailey and Bruce Allardice, "Debray, Xavier Blanchard" [Consultado en línea el 28 de marzo de 2017] http://www.tshaonline.org/handbook/online/articles/fde02.

${ }^{35}$ GLO: CC. Passim, including nos. 2038-2059, Old Docket, 1857-1860.

Sillares, vol. 1, núm. 1, 2021

DOI: https://doi.org/10.29105/sillares1.1-5 
evidencia. El comisario desestimó 100 solicitudes, en la mayoría de los casos por una de las razones analizadas arriba, y la legislatura rechazó 57 solicitudes que llegaron a sus manos. Según el registro de la comisión, durante este periodo el comisario emitió doce certificados de reemplazo y tres originales. ${ }^{36}$ El verdadero desastre para la comunidad mexicotejana no consistió en el rechazo de solicitudes sin mérito, sino en que tuvo un efecto negativo sobre la reputación de los mexicotejanos, considerándolos poco fiables.

Sin embargo, la conclusión es que existía un prejuicio en contra de denunciantes mexicotejanos no está basada sólo en la examinación del registro de la comisión. Anteriormente, en el año de 1858, la comisión especial compuesta de senadores y diputados nombrada para revisar las denuncias remitidas por el comisario, dictaminó un proyecto de ley que miembros de la cámara de representantes encontraron discriminatorio. El 6 de febrero de 1858, Ángel Navarro reiteró las acusaciones, que había declarado en noviembre anterior, referentes a la manera de proceder del comisario, y agregó nuevos alegatos de prejuicio por

\footnotetext{
${ }^{36}$ GLO: CC. Passim, including nos. 2038-2059, Old Docket, 1857-1860. La laboriosa tarea de revisar cada anotación del registro contra los expedientes individuales todavía no se ha emprendido.
} 
parte de la legislatura. ${ }^{37}$ Declaró el dictamen de la comisión especial como "la más palpable y flagrante injusticia en contra de una clase de individuos". Prosiguió señalando que desde que se había fundado la Comisión de Reclamaciones, los mexicotejanos habían sido un objeto de "gran injusticia". Le atribuyó la situación a un "quizás honesto, pero de todas maneras mal fundado, prejuicio en contra de esta clase de individuos".

Navarro continuó su discurso esbozando la injusticia con la cual la comisión había tratado a los mexicotejanos. No arguyó que no se hubiera cometido fraude, solo que eso no debía de enturbiar las reclamaciones legítimas. En cuanto a los dos primeros comisarios, ellos habían actuado arbitrariamente y de manera "no autorizada por la ley, observando ciertas distinciones de clases donde tales no se conocían ni en la constitución ni en las leyes". Además, incluso en los casos en que pruebas adicionales se habían presentado por dos respetables hombres blancos, "el comisario no había recomendado ni un solo certificado original".

El legislador mexicotejano entonces puso su mira sobre la comisión especial. Navarro no podía entender cuáles reglas podía

${ }^{37}$ ASG. "Legislative proceedings", February 5-6, 1858.

Sillares, vol. 1, núm. 1, 2021

DOI: https://doi.org/10.29105/sillares1.1-5 
haber adoptado la comisión para que la llevaran a aceptar sólo dos reclamaciones de mexicotejanos. "Pareciera que la comisión, al descubrir algunas reclamaciones palpablemente fraudulentas, estuviera disgustada con esta clase de solicitante y [hubiera] concluido rechazar el grupo entero en masa". Siguió que esto se hacía a pesar de que, hombres como Mirabeau B. Lamar y Joseph Lee (el presidente de la misma comisión), habían respondido por algunos de los testigos mexicotejanos. Quizás lo más irritante para Navarro era su conclusión de que al revisar la lista de las reclamaciones que esta comisión había rechazado, observó que en muchas de ellas las razones de la comisión para hacerlo se anotaban individualmente, pero en el caso de los reclamos de origen mexicano, se había procedido de otra manera. En estos casos, parece que la comisión no actuó después de examinar los méritos de cada uno, sino que rechazó todo lo que parecía mexicano por la sola razón de que habiendo falsas reclamaciones entre ellos, no se veía capaz de diferenciar.

Jack Latham, otro diputado con un electorado que incluía gran número de mexicotejanos, respaldó las quejas presentadas por Navarro y agregó dos propias. Primero, Latham observó que a los mexicotejanos sólo se les trataba de ciudadanos a la hora de 
votar o de pagar impuestos, "pero cuando piden derechos iguales bajo nuestras leyes, son negados, aunque nacieron y muchos siguen viviendo en Texas". Segundo, no existía razón para negar los reclamos de un grupo que había cumplido con la ley de la misma manera que otros denunciantes y que había sufrido los mismos altos costos para viajar a Austin a presentar sus reclamaciones.

El día anterior, Hamilton P. Bee, representante de Laredo, había hablado de otro tipo de discriminación en contra de los mexicotejanos. Objetó que, aunque todas las reclamaciones de su distrito se habían probado apropiadamente, habiendo respondido por los testigos tanto él como el juez de distrito E. J. Davis, ninguna de las solicitudes había sido aprobada por el comisario. Además, la comisión especial había visto bien otorgar certificados en casos procedentes de la parte oriental de Texas, mientras que rechazaba todas las reclamaciones procedentes al oeste del Río San Antonio.

Bee encontró ridículo que la comisión argumentara que "puede que haya algunos reclamos válidos entre ellos, pero a la comisión le es imposible distinguir", y se quejó de discriminación 
bajo dos formas. Primero, la comisión intentaba excluir a los mexicotejanos de recibir un beneficio legítimo bajo el equivocado argumento de que Texas no tenía jurisdicción sobre Laredo, mientras que el gobierno de Texas había reclamado esa parte del estado constantemente desde diciembre de 1835. Segundo, que, si los residentes del Río Grande habían sido ciudadanos desde el 2 de marzo de 1836 y podían presentar pruebas legales, tenían "tanto derecho a sus terrenos como cualquier otro ciudadano de la República de Texas, a no ser que la legislatura hiciera una distinción entre ciudadanos, algo que no se ha hecho y no se puede hacer bajo la constitución". 38

Basándose en estos argumentos, Jacob Waelder, el otro diputado por Béxar, propuso que el proyecto de ley se le devolviera a la comisión "con instrucciones que lo cotejara de tal manera que se traten igualmente a todos los reclamantes". Sin embargo, no fue así. Joseph Barnard, diputado por Goliad y sobreviviente de la llamada "Masacre de Fannin", 39 sacó a la luz

${ }^{38}$ ASG. Mr. Bee, "Legislative Proceedings", February 5, 1858.

${ }^{39}$ Ejecución de más de 300 rebeldes tejanos el Domingo de Palmas de 1836 en Goliad. Se habían rendido unos días antes, suponiendo que se les transportaría a Nueva Orleans. Sin embargo, a pesar de que varios oficiales mexicanos

Sillares, vol. 1, núm. 1, 2021

DOI: https://doi.org/10.29105/sillares1.1-5 
un tema que hasta ese momento se había evitado. No veía cómo se le podía pedir a la cámara de representantes no observar una distinción entre razas cuando "con muchos proyectos de ley para el relievo [sic] de negros libres, en las acciones tomadas sobre los voluminosos y hábiles dictámenes de sus comisiones sobre Kansas, y sobre la cuestión de la esclavitud, esta cámara enfáticamente ha reconocido distinciones entre las razas". Concluyó su discurso añadiendo: “¿ha de haber una distinción entre las razas en . . Texas oriental, pero ninguna en el oeste [de Texas]? Espero que los señores reconozcan las consecuencias del punto antes de que lo admitan". En consecuencia, la propuesta fue rechazada y el dictamen de la comisión fue aprobado abrumadoramente por la cámara de representantes. Para la mayoría de los diputados, tratar un asunto sobre los mexicotejanos era tratar un asunto sobre otra raza.

No tardó en llegar a San Antonio la noticia de la acción de la legislatura. El periódico San Antonio Texan comentó favorablemente sobre la acción de la legislatura, usando vívidas palabras al describir muchas de las reclamaciones. "Ni una en

pidieron clemencia por ellos, el general Santa Anna ordenó que se pasaran por las armas. 
veinte" hubiera sido otorgada al reclamante original, según el editor, pues las reclamaciones habían sido "compradas en casi nada por personas que buscan obtener su sustento de cualquier manera menos por su esfuerzo personal". En coplas, añadió que los especuladores "Esperaban ser ricos / Estafando el estado". ${ }^{40}$ Concluyó culpando a los especuladores por la pérdida de confianza por parte de la legislatura hacia todos los reclamos, privando así a los meritorios "de sus beneficios legales". ${ }^{41}$

El San Antonio Ledger, que reprodujo el artículo del Texan, defendió a los solicitantes argumentando que la mayoría habían sido honestos, muchos de ellos viudas y huérfanos. La mayoría de las reclamaciones todavía seguían en manos de los reclamantes originales "y las excepciones se habían comprado a precios justos, después de que el comisario había declarado que estaba completamente satisfecho, no sólo con las pruebas sino con la justicia de las reclamaciones". Esto, por supuesto, era una exageración, ya que hemos visto que desde el principio el comisario se había negado a recomendar los reclamos de mexicotejanos.

40 "Hoped to become great, by duping the state".

${ }^{41}$ San Antonio Ledger, February 27, 1858.

Sillares, vol. 1, núm. 1, 2021

DOI: https://doi.org/10.29105/sillares1.1-5 


\section{Conclusiones}

Aunque mi investigación sigue, me permito presentar unas conclusiones tentativas. Primero, las actividades en torno a la Comisión de Reclamaciones reforzaron estereotipos y le dieron a los racistas angloamericanos herramientas para poder degradar el estatus de los mexicotejanos. Para ellos, los mexicotejanos en su conjunto no eran confiables y estaban dispuestos a participar en el más siniestro fraude. Este parecer se aceptó a pesar de que había evidencias considerables de un descontrolado fraude de la misma índole en las porciones angloamericanas del estado. En consecuencia, a pesar de una igualdad constitucional entre anglotejanos y mexicotejanos, le fue permisible a los oficiales del estado imponer una carga de prueba más onerosa a éstos que a aquellos, y tratar a un grupo como conjunto, pero al otro de manera individual.

Segundo, el valor de la ciudadanía de los mexicotejanos fue puesta en duda. Aunque el derecho tejano y el Tratado de Guadalupe Hidalgo hicieron ciudadanos a los mexicanos que vivían al norte de la nueva frontera, esa ciudadanía estaba sujeta a una interpretación arbitraria. La mayoría de los legisladores no tuvieron problema en cambiar la fecha en la que la zona fronteriza 
entre el Nueces y el Bravo se incorporó a Texas, de manera que podían negarle beneficios a los mexicanos de esa región mientras se les extendían a los anglotejanos. Es decir, por un lado, los títulos mexicanos emitidos después del 2 de marzo de 1836 no eran válidos porque las autoridades mexicanas ya no tenían jurisdicción al norte del Bravo, y por el otro lado, los mexicanos residentes en esa zona no tenían derecho a beneficios en Texas hasta después de la anexión de Texas a Estados Unidos.

Tercero, tanto los especuladores escrupulosos como los que no lo eran tomaron ventaja de los mexicotejanos y contribuyeron al deterioro de sus derechos. Al presentar reclamaciones falsas o engañosas, y haciéndolo de manera obviamente descuidada, le hicieron fácil a la legislatura argüir que la reputación de los reclamantes mexicotejanos estaba mancillada. Peor aún fue que algunos de los especuladores usaron su posición de confianza dentro de la comunidad mexicotejana para llevar a cabo sus planes. Desconociendo el nuevo idioma y la nueva ley anglosajona, muchos mexicotejanos aparentemente se convirtieron en socios involuntarios de un complot de fraude en contra del estado. 
Los mexicotejanos todavía pudieron recibir justicia individualmente $\mathrm{y}$ contaron con representantes, tanto mexicotejanos como anglotejanos, que defendieron sus intereses enérgicamente. Sin embargo, es claro que tales casos constituyeron una minoría y que la constitución y leyes del estado no fueron absolutas. Así como en la economía y en las relaciones sociales, las ideas de raza y cultura determinaron la posición legal en la sociedad tejana. En un grado considerable, el trato injusto a los mexicotejanos en la obtención de derechos de suelo contribuyó al proceso de discriminación y segregación que se siguió acrecentando hasta mediados del siglo XX.

\section{Referencias}

\section{Archivo}

Gammel's Laws of Texas

Texas General Land Office (GLO)

\section{Bibliografía}

Bailey, Anne J., y Bruce Allardice. "Debray, Xavier Blanchard". Handbook of Texas Online, 1952. http://www.tshaonline.org/handbook/online/articles/fde02 
Carrigan, William D., y Clive Webb. Forgotten Dead: Mob Violence against Mexicans in the United States, 18481928. New York: Oxford University Press, 2013.

Carroll, Mark M. Homesteads Ungovernable: Families, Sex, Race, and the Law in Frontier Texas, 1823-1860. Austin: University of Texas Press, 2001.

De La Teja, Jesús F., ed. A Revolution Remembered: The Memoirs and Selected Correspondence of Juan N. Seguín. Austin: Texas State Historical Association, 2002.

De León, Arnoldo. They Called Them Greasers: Anglo Attitudes Toward Mexicans in Texas, 1821-1900. Austin: University of Texas Press, 1983.

Eakle Dobkins, Betty. The Spanish Element in Texas Water Law. Austin: University of Texas Press, 1959.

Greaser, Galen D., y Jesús F. De La Teja. "Quieting Title to Spanish and Mexican Land Grants in the Trans-Nueces: The Bourland and Miller Commission, 1850-1852". Southwestern Historical Quarterly 95, núm. 4 (1992): 445-64.

Hart, James P. "Oil, the Courts, and the Railroad Commission". Southwestern Historical Quarterly 44, núm. 3 (1941): 303-20.

Hawkins, Walace. El Sal del Rey: Fixing Title to. Austin: Texas State Historical Association, 1947.

Miller, Thomas Lloyd. The Public Lands of Texas, 1519-1970. Norman: University of Oklahoma Press, 1972. 
Montejano, David. Anglos and Mexicans in the Making of Texas, 1836-1986. Austin: University of Texas Press, 1987.

Pitts III, John Bost. "Speculation in Headright Land Grants in San Antonio from 1837 to 1842 ". Tesis de maestría, Trinity University, 1966.

Porter Jr., Charles R. Spanish Water, Anglo Water: Early Development in San Antonio. College Station: Texas A\&M University Press, 2009.

Rosenbaum, Robert J. Mexicano Resistance in the Southwest: "The Sacred Right of Self-Preservation". Austin: University of Texas Press, 1981.

Sayles, John, y Henry Sayles. A Treatise on the Laws of Texas Relating to Real Estate, and Actions to Try Title and for Possession of Lands and Tenements. St. Louis: The Gilbert Book Company, 1890.

Stuntz, Jean. Hers, His, and Theirs: Community Property Law in Spain and Early Texas. Lubbock: Texas Tech University Press, 2005.

Taylor, Paul S. An American-Mexican Frontier: Nueces County, Texas. New York: Russell \& Russell, 1971.

Thompson, Jerry D. Cortina: Defending the Mexican Name in Texas. College Station: Texas A\&M University Press, 2007.

Young, Elliott. Catarino Garza's Revolution on the TexasMexico Border. Durham: Duke University Press, 2004. 